\title{
TEORIA DA INFORMAÇÄO COMO INSTRUMENTO DE PESQUISA NA INTEGRAÇÃO VERBAL ENTRE O PORTADOR DE AIDS E A EQUIPE DE ENFERMAGEM
}

\author{
Gir, Elucir* \\ Moriya, Tokico Murakawa* \\ Dela Coleta, José Augusto** \\ Stephaneck, Paul*** \\ Pelá, Nilza Tereza Rotter*
}

Gir, E et al. Teoria da informação como instrumento de pesquisa na interação verbal entre o portador de AIDS e a equipe de enfe magem. Rev.Esc.Enf. USP.,v. 27, n. 1, p. 107-16, abr. -1993

Objetivou-se testar o emprego de variáveis contidas no modelo da Teoria da Informação em estudo de interaçäo verbal entre Aidéticos e equipe de enfermagem. Os resultados obtidos evidenciam que o emprego do cálculo da variabilidade aos dados contidos em matriz SAVI enriquece os dados estatísticos, permitindo que a qualidade do diálogo em questäo seja avaliada.

UNITERMOS: Conunicação. Sindrome de imunodeficiência adquirida. Equipe de enfermagem.

\section{INTRODUÇÄO}

A comunicação é considerada por vários autores (SUTTERLEY; DONNELY, 1973 e MORTENSEN, 1980) como um dos processos básicos do ser humano ao longo de sua trajetória vital, c a mais complexa e elevada conquista da humanidade.

Para MASER (1975), etimologicamente, a palavra "comunicar" deriva do latim., significando "por em comum, partilhar, trocar opiniōes, conferenciar". É um vocábulo que se tornou popular através dos tempos sendo atualmente empregado para denominar a relação entre as pessoas, falando em sentido geral.

O processo global da comunicação é dotado de sentido amplo, envolvendo meios verbais e não verbais pelos quais uma pessoa pode influenciar a outra. WEAVER (1980) destaca alguns meios quc o homem utiliza para transmitir idéias: a palavra falada, dirctamente ou por telefone ou rádio; a palavra escrita ou impressa, emitida pela mão ou equipamento; acenos de cabeça, de mão;

\footnotetext{
* Docente jun Ribeirāo Preto - USP.

* * Docenle do Departamento de Psicologia da Universidade Federal de Uberlândia - MG.

*** Docente jun wo ao Departamento de Psicologia da Faculdade de Filosofia, Cićncias e Letras de Ribeirão Prew - USP.
} 
piscadelas; gestos; trecho musical que nos lembra um fato; movimentos e posiçōes corporais.

Quanto aos modelos de processo de comunicação, BERLO (1979) menciona os desenvolvidos por Schram, Westley; Macclean, Fearing, Johnson, relatando que há similiaridades entre eles, bem como diferenças, principalmente no que tange à terminologia e número de elementos. Entretanto, o modelo básico de comunicação desenvolvido por Shannon; Weaver é considerado o mais divulgado na descriçāo da comunicação humana.

Para BERLO (1979) os ingredientes básicos de processo de comunicação são: Fonte, Mensagem, Canal e Receptor. Esses elementos apresentam relação com a Teoria da Informação ou teoria matemática da comunicação, como é denominada por WEAVER (1980).

Conforme ressalta LITTLEJOHN (1982), historicamentc esta teoria é "prima" da teoria dos sistemas e da cibernética e desenvolveu-se, fundamentalmente, a partir de investigações independentes nos campos da física, engenharia e matemática, cujo elemento comum era a percepção de que a organização ć uma questão de probabilidade.

A teoria da informação, conforme elucida WEAVER (1980), não constitui fato inovador, visto que como observou o matemático John Von Neumann, no século XIX, o físico austríaco Ludwig Boltzmann já havia sugerido que alguns conceitos de mecânica estatística cram aplicáveis ao conceito de informação.

Releva-se entretanto que, apesar dos seus pressupostos teóricos terem sua base identificada no século XIX, somente nos últimos 30 anos 6 que tem se destacado o seu domínio teórico no processo básico da comunicação, ou seja,a informação.

A teoria da informação, que é fundamentalmente uma formulação matemática, ć uma perspectiva que se concentra no estudo quantitativo da informação, em mensagens $\mathrm{c}$ do fluxo de informações entre emissores $\mathrm{e}$ receptores. MUCCHIELLI (1971) coloca que o interesse desta teoria é voltado às propriedades intrínsecas e quantitativas das mensagens, do ponto de vista de seus efeitos sobre o receptor, independentemente do seu significado.

Esta teoria, de maneira geral, está diretamente associada aos ingredientes básicos do processo de comunicação. Portanto, para que um estímulo $\mathrm{X}$ provoque uma resposta $\mathrm{Y}$, é imprescindivel que exista uma perfeita articulação entre esses elcmentos. As falhas contribuem para que a mensagem emitida não seja devidamente recebida, fazendo com que o processo de comunicação deixe de se viabilizar precisa e eficientemente.

Reconhecendo a importância de uma informação precisa e coerente no relacionamento interpessoal, a realização destc estudo tem com objetivo testar o emprego de variáveis contidas no modelo da Teoria da Informação $\mathrm{cm}$ estudo de interação verbal paciente c equipe de enfermagem. 


\section{METODOLOGIA}

A amostra constituiu-se da observação de três pacientes com diagnóstico de AIDS e 17 elementos da equipe de enfermagem, enquanto desempenhavam suas atividades profissionais, dentro da enfermaria destes pacientes. Contouse com quatro observadores, previamente treinados e calibrados para efetuarem o registro de todo episódio verbal observado, valendo-se de técnicas de observação do tipo relato cursivo e registro com lápis e papel. Elaborou-se um protocolo para cada paciente que foi submetido a três juízes para efetuarem a divisão dos episódios verbais em unidades e a classificação, segundo sistema SAVI (System of Analysis of Verbal Interaction).

Este sistema tem como fio condutor uma matriz, que é uma grade preconizada por SIMON; AGAZARIAN (1967), formada por 28 linhas e 28 colunas, que representam novas áreas de Comportamentos verbais, ou seja: A, B, C, D, $\mathrm{E}, \mathrm{F}, \mathrm{G}, \mathrm{H}, \mathrm{J}$. Cada área é denominada, considerando-se que o comportamento verbal pode ser classificado como um comportamento que se aproxima ou afasta a informaçāo pessoal e/ou temática. Em outras palavras, o comportamento de afastamento relaciona-se a mensagens contraditórias, obscuras e os de aproximação a mensagens claras e não contraditórias.

Cada área é definida por um conjunto de categorias que, no total somam 28. A matriz SAVI contém, portanto, 784 células, sendo que cada célula corresponde a um ponto de intersecção entre duas categorias - a emitida e a recebida, como expresso na Figura 1. 
FIGURA 1. Matriz SAVI: 9 áreas, 28 categorias, 784 células

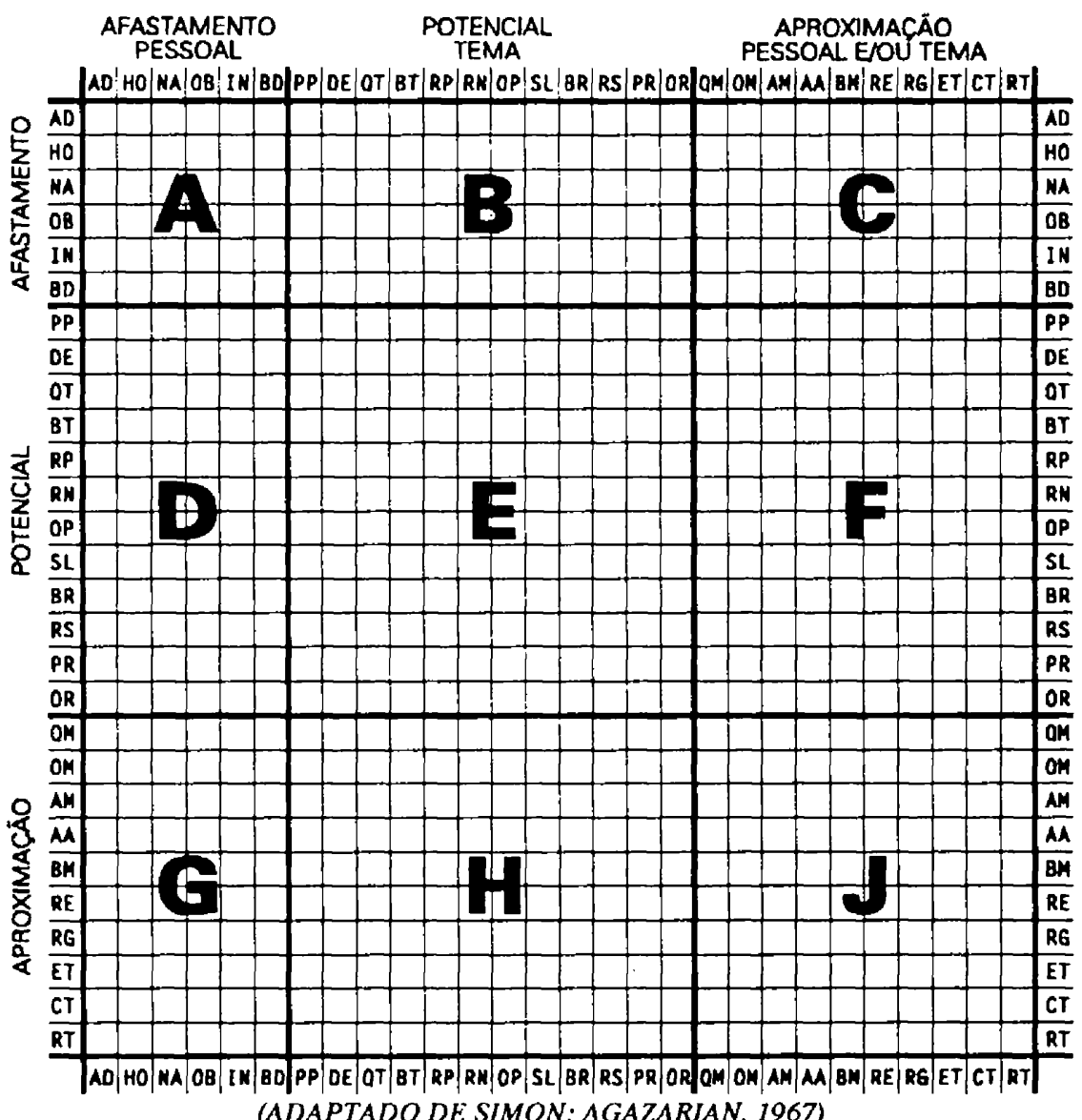

Legenda: $A D=$ auto defesa; $H O=$ hostilidade; $N A=$ narrativa; $O B=$ obrigatoriedade; IN $=$ intelectualidade; $B D=$ brincadeira defensiva; $P P=$ participaçāo pessoal; $D E=$ descriçaio; $Q T=$ questão sobre o tema; $B T=$ brincadeira sobre o tema; $R P=$ resposta positiva; $R N=$ resposta negativa; $O P=$ opiniäo; $S L=$ silêncio; $B R=$ barulho; $R S=$ riso; $P R=$ proposta $O R=$ ordem; $Q M=$ questão de manutenção; $O M=$ oferece manutenção; $A M=$ apoia manutenção; $A A=$ auto afirma; $B M=$ brincadeira de manutençào; $R E=$ resposta específica; $R G=$ resposta geral; $E T=$ esclarecimento sobre o tema; $C T=$ construçäo do tema; $R T$ = reflexĩo sobre o tema.

Áreas: $A$ = afastamento de manutenção pessoal; $B=$ afastamento do tema; $C=$ afastamento do tema elou da manutenção pessoal; $D=$ aproximação elou afastamento potencial de manutenção pessoal; $E$ = aproxinação elou afastamento potencial do tema; $F$ = aproximação e/ou afastamento potencial do tema e/ou manutenção pessoal; $G$ = aproximação de manutençäo pessoal; $H=$ aproximação do tema; $J$ = aproximação do tema elou pessoal. 
Após o julgamento das unidades, lançavam-se os dados na matriz SAVI, respeitando-se os elementos emissores e receptores e procedía-se à análise baseada em programa para o processamento cletrônico dos dados para o cálculo da variabilidade e da quantidade de informaçăo transmitida.

Para o cálculo da quantidade de informaçāo transmitida, expressa pela letra $R$, empregou-se a fórmula preconizada por FAVERGE (1954) e STEPHANECK (1971), ou seja:

$$
\begin{aligned}
& R_{\text {relativo }}=\frac{R_{\text {enual }}}{\log \text { do menor } i \text { ou } j} \text {, onde } \\
& R_{\text {atual }}=\frac{\Sigma n_{i j} \log _{2} n_{i j}-\Sigma n_{1} \log _{2} n_{i}-\Sigma \log _{2} n_{i}+N \log _{2} N}{N} \\
& \text { sendo: } \\
& n_{i j}=n^{e} \text { de respostas contidas na intersecça de linha i da coluna } j \\
& \eta=\text { número de respostas total na linha } i \\
& \eta=\text { número de respostas total na coluna } j \\
& N=\text { número do respostas total na tabela } \\
& \Sigma=\text { menor } i \text { ou } i=\mathbf{2 8}
\end{aligned}
$$

R, conforme elucidam FAVERGE (1954) e STEPHANECK (1971), define estatística de correlação entre duas variáveis (x c y), que correspondem, respectivamente, a emissão e recepção das informações. Tem sempre valor positivo ou nulo e deve ser calculado, usando logarítmos na base 2 .

Localizando $\mathbf{R}$ num diagrama uc Venn, representativo das várias quantidades de informações implicadas num sistema de transmissão, tem-se, conforme citaçōes de EDWARDS (1964) e STEPHANECK (1971):

\section{Onde:}

$R=$ quantidade de informaçào transmitida,

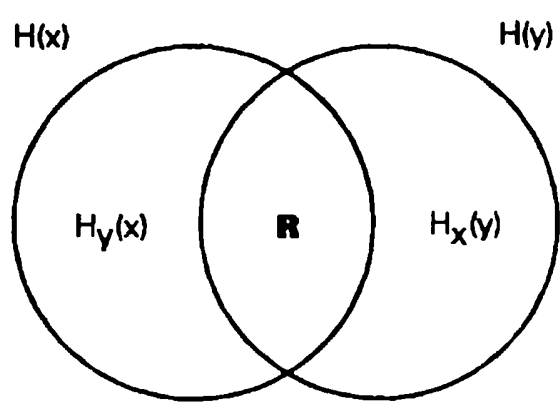

$H(x, y)$ isto é, informaçáo emitida (presente na entrada) e recebida (presente na saida); $H(x)=$ entropia da fonte ou quantidade de informação emitida pela fonte; $H(y)=$ entropia da recepção ou quantidade de informaçào contida na resposta do sujeito;

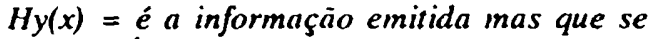
perdeu. É chamado de "equivoco"; $H x(y)=e ́$ a informação recebida, ou seja, informação presente na saida mas não na entrada. E o que se chama de ambigüidade ou ruido.

$H(x, y)=$ entropia total ou quantidade total de informação presente no sistema. 


\section{RESULTADOS}

De posse da classificação das unidades verbais com base nos pressupostos teoricos de SIMON; AGAZARIAN (1967), passou-se ao lançamento dos dados na matriz SAVI.

O lançamento dos 3336 comportamentos verbais trocados entre os pacientcs obscrvados e a equipe de enfermagem que os assistiram -durante um total de $90 \mathrm{hs}$ de observaçăo- fe $z$ com que fossem identificadas as áreas de comportamentos verbais prioritárias e os comportamentos verbais mais frequentemente emitidos. Para tal identificação, utilizaram-se cálculos de frequência simples e percentual.

Procedeu-se ao cálculo da quantidade de informação transmitida, em rclação ao quadrante como um todo c segundo cada área c receptor - emissor. Para tanto, isolaram-se as árcas a fim de se ter melhor visualizaçāo dos totais marginais e mesmo do cálculo de $R$, conforme pode-se observar nos Quadros 1 c 2 .

(Outros quadros podem ser consultados em GIR (1988))

Dos dados apresentados, relativos aos valores correspondentes à variabilidade, ou seja $\mathrm{R}$, em cada matriz despontam os valores mínimos e máximos obtidos.

Nos dois exemplos citados (Quadros 1 c 2), o valor mínimo de $\mathbf{R}$ obtido foi de $\mathbf{0 , 0 4 0 5}$, correspondente à área $F$ da matriz cuja interação se deu entre a equipe de enfermagem e os pacientes $\mathrm{P}_{1}, \mathrm{P}_{2}, \mathrm{P}_{3}$; enquanto em relação aos quadrantes totais destaca-se o $R_{A}$-J da matriz $P_{1} P_{2} P_{3}-E q$, onde se identificou $\mathrm{R}=0,0448$.

Com respeito aos valores máximos devem ser destacados os valores de $R$ $=0,3065$, que resultou da área $F$, da matriz $P_{-}$Eq $\mathrm{C}_{\mathrm{A}-\mathrm{J}}=0,1309$ obtido no quadrante $\mathrm{P}_{1} \mathrm{P}_{2} \mathrm{P}_{3}-\mathrm{Eq}$. 
QUADRO 1 - Distribuiçāo da Quantidade de Informaçāo transmitida na interação verbal entre os pacientes $\mathrm{P} 1, \mathrm{P} 2$ e $\mathrm{P} 3$ e a equipe de enfermagem, segundo as áreas do sistema SAVI e emissor P1 P2 P3 e receptor Equipe de Enfermagem (Eq).

$R_{\Lambda}=0$
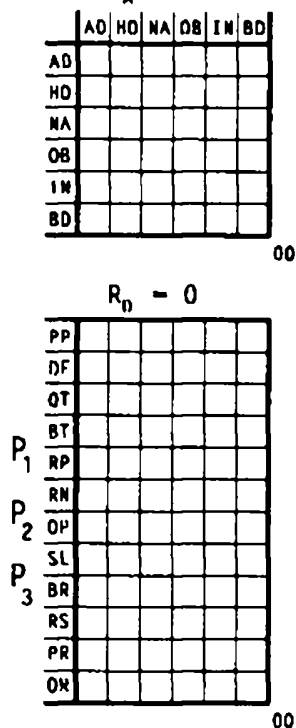

$R_{t}=0$

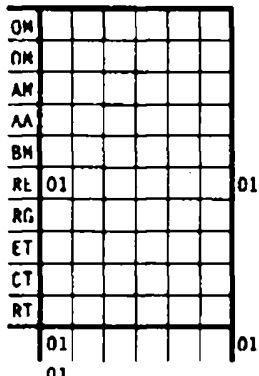

Eq

$R_{\mathrm{h}}=0$

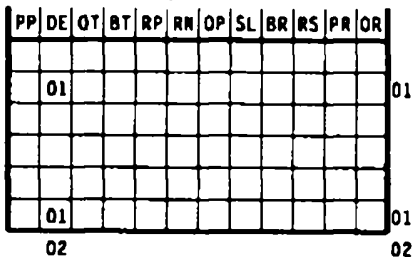

$R_{E}=0.0780$

\begin{tabular}{|c|c|c|c|c|c|c|c|c|c|c|}
\hline & 21 & 23 & & 0.1 & & 08 & 09 & 03 & 18 & 86 \\
\hline & 27 & 27 & 03 & 03 & 01 & 04 & 06 & 02 & 11 & 184 \\
\hline 02 & 09 & 18 & & 0.3 & & 02 & 01 & & 04 & .30 \\
\hline & & & & & & & & & & \\
\hline & 07 & 16 & & ou & & 02 & 25 & 04 & 09 & 67 \\
\hline & 01 & 03 & & & & 01 & & & & 05 \\
\hline 01 & 06 & 07 & & 02 & & 03 & 02 & 03 & 02 & 26 \\
\hline 01 & 16 & 48 & 02 & 30 & & 03 & & 10 & 25 & 134 \\
\hline & & & & & & & & & & \\
\hline & & 01 & & & & 01 & 01 & & & 03 \\
\hline & 02 & 01 & & & & & 03 & 03 & 01 & 10 \\
\hline & $\mathrm{OA}$ & OA & & 0.3 & & 02 & 0.3 & 04 & & $P h$ \\
\hline
\end{tabular}

$R_{H}-0.0503$

\begin{tabular}{|c|c|c|c|c|c|c|c|c|c|c|c|}
\hline & 06 & 02 & & 01 & 01 & 01 & 04 & & 01 & & in \\
\hline & 01 & 05 & & 02 & & 02 & & & 03 & 02 & 14 \\
\hline & & & & & & & & & & & \\
\hline & & & & & & & & & & & \\
\hline & 01 & 02 & & & & & & 02 & & & 105 \\
\hline 02 & 56 & 59 & 01 & 21 & & 10 & 15 & & 23 & 29 & 206 \\
\hline & 11 & 07 & & 01 & & 03 & 05 & & 03 & 02 & 32 \\
\hline & 02 & & & & & & & & 01 & 01 & 04 \\
\hline & & & & & & 01 & & & & & 01 \\
\hline & 07 & & & & & & & & & 101 & 0.3 \\
\hline & 79 & & 01 & 15 & 01 & 17 & & & & 34 & 281 \\
\hline
\end{tabular}

$R_{A \rightarrow \infty}=0.1309$

$$
R_{C}=0
$$

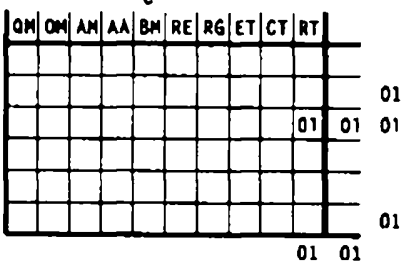

$$
R_{F}=0.3065
$$

\begin{tabular}{|l|l|l|l|l|l|l|l|l|l|ll}
\hline 02 & 01 & 08 & 01 & 01 & & & & & 01 & 17 & 103 \\
\hline 06 & & 01 & & & & 01 & 03 & 01 & 03 & 15 & 99 \\
\hline 02 & & & & & 51 & 14 & 04 & & 01 & 1.3 & 112 \\
\hline & & & & 01 & & & & & & 01 & 1 \\
\hline 01 & & 02 & & & & & & & & 0.3 & 20 \\
\hline 02 & & & & & & & & & & 02 & 7 \\
\hline 02 & & 01 & & & & & & & 01 & 04 & 30 \\
\hline 06 & & 01 & & & & & & & & 07 & 141 \\
\hline & & & & & & & & & & \\
\hline & & 01 & & & & & & & & 01 & 1 \\
\hline & & & & & 04 & 01 & 01 & & & 06 & 16 \\
\hline 01 & & 02 & & 01 & 02 & & 07 & & & 08 & 34 \\
\hline
\end{tabular}
$R_{\mathrm{J}}-0.2828$

\begin{tabular}{|l|l|l|l|l|l|l|l|l|l|ll}
\hline 02 & & 01 & & & 28 & & & & 01 & 37 & 48 \\
\hline & & 03 & & & & & & & 01 & 04 & 04 \\
\hline & & & & & & & & & & & \\
\hline & & & & & & & & & & & \\
\hline & & & & & 01 & & & & & 01 & 06 \\
\hline 21 & 01 & 02 & 01 & 01 & & & 03 & & 06 & 38 & 215 \\
\hline 08 & & 01 & & & & & & & 02 & 11 & 13 \\
\hline & & & & & 01 & & 03 & & & 10 & 11 \\
\hline & & & & & & & & & & & 01 \\
\hline & & & & & & & & & & & 03 \\
\hline 34 & 01 & 01 & 01 & 01 & 36 & & 05 & & 10 & 96 & \\
\hline 56 & 02 & 23 & 02 & 04 & 93 & 16 & 17 & 01 & 20 & & 998
\end{tabular}

998 
QUADRO 2. Distribuição da quantida de de informação trans mitida na interaçāo verbal entre os pacientes $\mathrm{P} 1, \mathrm{P} 2, \mathrm{P} 3$ e a equipe de enfermagem, segundo as áreas do sistema SAVI c emissor e Equipe de Enfermagem (Eq) e receptor P1 P2 P3.

$R_{A}-0$

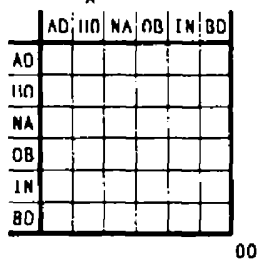

$R_{1)}=0$

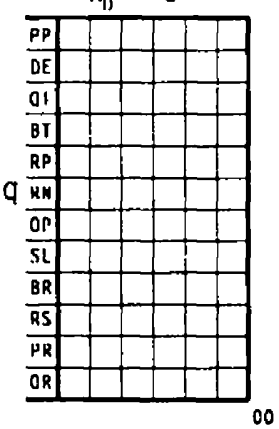

$R_{G}-0$

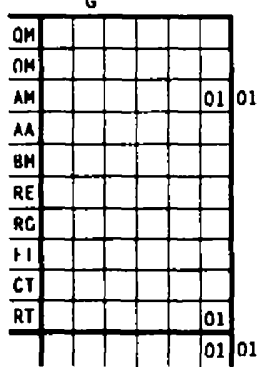

$$
P_{1} P_{2} P_{3}
$$$$
R_{B}=0
$$

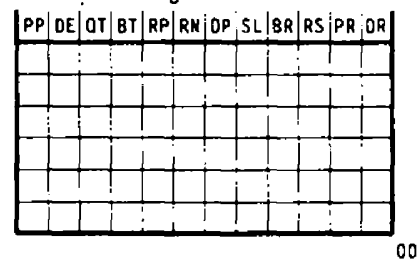

$$
R_{\mathrm{E}}=0.0413
$$

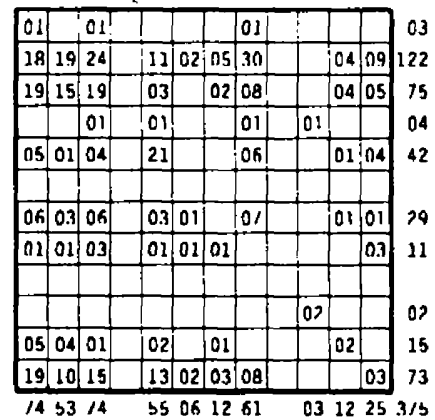

\begin{tabular}{|c|c|c|c|c|c|c|c|c|}
\hline 07 & 03 & 12 & 10 & 06 & 10 & & & 01 \\
\hline 01 & & & 01 & & & & & \\
\hline 05 & 03 & & 05 & 02 & 02 & & & \\
\hline 01 & & & & & & & & 01 \\
\hline 01 & 01 & & & & & 01 & 01 & 01 \\
\hline 03 & 08 & 06 & 02 & 03 & 04 & & & 103 \\
\hline 01 & 01 & 02 & & & 01 & & & \\
\hline 05 & n1 & 03 & & 02 & 01 & & & 01 \\
\hline & & & & & & & & \\
\hline 0.1 & 02 & 011 & & 02 & 02 & & & \\
\hline 25 & 19 & 24 & 18 & 15 & 20 & $01 \mid$ & & $|n\rangle$ \\
\hline 99 & 72 & 98 & 73 & 27 & 81 & 04 & 13 & 32 \\
\hline
\end{tabular}

$$
R_{H}=0.0451
$$

$$
R_{A \rightarrow J}=0.0448
$$

$$
R_{C}-0
$$
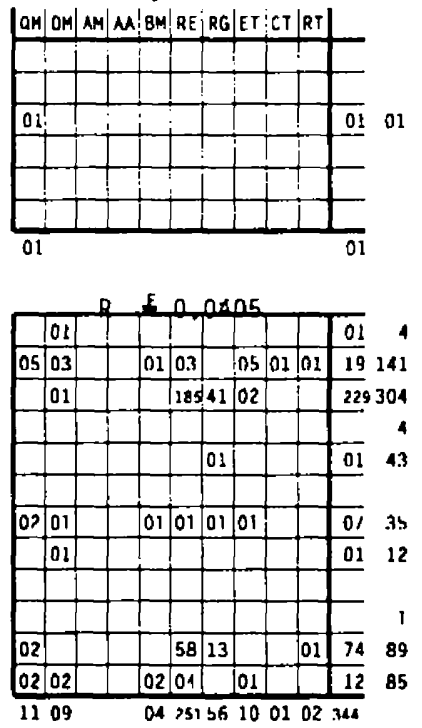

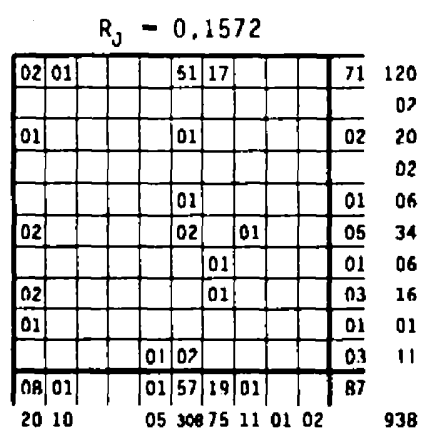




\section{DISCUSSĀO E CONSIDERAÇŌES FINAIS}

O emprego da Teoria da Informação, representado pelo cálculo de $\mathrm{R}$, em dados contidos em matriz SAVI, veio contribuir para que fosse evidenciada a qualidade de interação tida entre a equipe de enfermagem c pacientes aidćti$\cos$.

Conforme elucida STEPHANECK (1971), $\mathrm{R}$ tem sempre valor positivo ou nulo; sendo nulo quando as distribuições de $\mathrm{x}$ e y são independentes, portanto um diálogo estercotipado, repetitivo. Quanto maior for o valor de R, ou seja, quanto mais distante estiver de zero, maior é a quantidade de informação transmitida entre as pessoas e, logicamente, maior será a variabilidade no điálogo e mais rica a interação.

Os valores de $\mathbf{R}$ obtidos nesta investigaçāo vêm sugerir, portanto, que as interações verbais tidas entre os pacientes e a equipe de enfermagem, tendem a se distanciar da estcreotipia, ou seja, de um diálogo viciado, onde seriam obtidos padrões de respostas pré estabelecidas. Por outro lado, crê-se ser uma questão que, se trabalhada, pode oferecer diálogos mais ricos, com valores de $R$ mais elevados.

A teoria da informação é uma consequência direta do pós-guerra na indústria de telecomunicaçōes e hoje tem aplicações muito práticas nas ciências eletrônicas de computaçāo, onde é imprescindível avaliar quantidades de informação, projetar canais, transmissores, receptores e códigos que facilitam a manipulação da informaçāo, além de oferecer contribuiçōes à comunicação social (LITTLEJOHN, 1982).

Esta teoria auxilia a esclarecer problemas técnicos, ou seja, os que tratam da exatidão da transmissāo de informações; problemas semânticos, que se preocupam com o significado da informação para a fonte e receptor e os problemas de nível da eficiência que se relacionam à influência da informação sobre o receptor.

Apesar da sua relevante aplicabilidade, pelo levantamento bibliográfico realizado, detectou-se a inexistência do emprego deste tratamento estatístico na enfermagem ou mesmo em situaçōes hospitalares. FAULKNER (1979), Stockwell (1972) apud CLARK (1981), afirmam que os diálogos entre enfermeiras e pacientes tendem a ser superficiais e estereotipados, comentando ainda quão inadequada é esta comunicaçāo. Estes comentários, entretanto, nāo se embasam na Teoria da Informaçāo.

Este fato gera inquietaçāo na medida em que se faz refletir sobre o conhecimento e aplicabilidade dos instrumentos pela área da enfermagem. Um outro aspecto que conduz a dificuldades é a impossibilidade de comparar estes dados aos obtidos em outras pesquisas e somar subsídios para interpretar os resultados presentes. 
O emprego do cálculo da variabilidade - baseado na Teoria da Informação - permite identificar o tipo de interação que está ocorrendo e o quanto o diálogo é rico ou não. A aplicação deste cálculo aos dados contidos na matriz SAVI foi pertinente e enriquece os dados estatísticos. Trata-sc, portanto de um tratamento de indiscutível importância, podendo bem contribuir para o enriquecimento das pesquisas c consequentemente para a prática aplicada.

GIR, E. et al. The information theory in study that deals with verbal interaction betwcen AIDS patients and nursing team. Rev. Esc. Enf. USP., v.27, n.1, p.107-16, apr 1993.

The objective of this paper was to verify the use of variables included in the information Theory in study that deals with verbal interaction between AIDS patients and Nursing team. The results showed that the use of the variability calculation in data retained in SAVI matrix improves the statistical data and permit that the quality of the dialogue can be evaluated.

UNITERMS: Communication. Adquired immonodeficiency sy ndrome. Nursing tea m.

\section{REFERENCIAS BIBLIOGRÁFICAS}

BERLO, D.K. Q processo da comunicacāo: introduçāo à teoria a à prática. Sāo Paulo, Martins Fontes, 1979. p. $11-75$

EDW ARDS, E. Introducāoà teoria da informaço. Sāo Paulo, Cul tri x/EDUSP, 1971.

FAULKNER, A. Monitoring nurse: patient conversation in a ward. Nurs. Jimes, v. 75, n. 23, p. 95-6, 1979.

FAVERGE, J.M. Note sur quclques stati sques empruntées a la theoric de l'information. Bull. Centre d'etudes el Recherches Psychotechniques, v. 3, n. 1, p. 2, 1954.

GIR, E. Intcração verbal entre a equipe de enfermagem c pacientes aidéticos. Ri beirāo Preto, 1988. 210p. Dissertaçāo (Mestrado) - Escola de Enfermagem de Ribei răo Preto, Universidade de São Paulo.

LITTLEJOHN, S.W. Eundamentos teórious da comunicacāo humana. Rio de Janciro, 7ahar, 1982, p. 152-61.

MASER, S. Fundamentos de lecria geral da comunicaçāo: uma introduçāo a seus métodos $\mathrm{c}$ conceitos fundamentais, acompanhada de cxerćcio. São Paul o, EPU/EDUSP', 1975, p. 1-9.

MORTENSFN, C.D. Teoria da comunicağa: te tos básicos. São Paulo, Mosaico, 1980.

MUCCIIIF.LI, R. Communication el nescaux de communications. Librai res Techniques, enterprise moderne d'edition, 1971, 69p.

SIMON, A.; AGAZARIAN, Y. Sequentialanalysis of verbalinteraction. Philadelphia, 1967. 109p.

SIYIEPHANECK, $P$. Efeito da incerteza no tratamento da informaçāo pelo sujeito humano. Ara Bras.Psic.Aplic, Rio de Janeiro, v. 23, n. 1, p. 272-38, 1971.

STOCKWELL, F. The unpopular patient. Royal Col lege of Nursing, London, 1972. apud Cl.ARK, J.M. Communication in nursing. Nurs Times, v. 77, n. 1, p. 12-8, 1981.

SUTTERLEY, D.C.; DONNELLY, G.F. Pespectives in human deved opment: nursing throughout the life cycle. Philadelphia, LB. Lippincot, 1973.

WEA VER, W. A matemática da comunicaçāo. In: MORTENSEN, C.D. Teoria da compnicaçāo: textoo básicos. São Paulo, Mosaioo, 1980. p. 39-51. 